\title{
Strategic group theory: A customer-oriented view
}

\author{
Y. Datta \\ (College of Business, Northern Kentucky University, Highland Heights KY 41099, USA)
}

\begin{abstract}
Barney and Hoskisson (1990) argue that the strategic group research has neither established the existence of strategic groups, nor their relationship to firm performance. The primary reason behind the unsatisfactory results is the lack of a theoretical framework: what strategic variables to include in the analysis and their relative importance; the definition of an industry; and how to make competitive strategy operational. First, the author presents a customer-oriented theory of management which submits that, like Procter and Gamble, understanding customers should be the primary focus of a business. Second, the author proposes an integrated approach to competitive strategy. Because customer-perceived quality is far more critical to long-term success than any other factor, it should be the centerpiece of competitive strategy. The author suggests that competitive strategy should be divided in two interdependent dimensions: external and internal. It is the external strategy that should be considered the primary dimension because it reflects the customers' perspective, and provides a sense of direction regarding how the internal resources should be used. Next, the author presents an operational framework of competitive strategy which proposes that the best route to market share leadership in consumer markets is competing in the mid-price segment, offering superior quality compared to competition at a somewhat higher price: (1) to maintain an image of quality, and (2) to ensure that the strategy is profitable and sustainable. Finally, the author offers a framework of business or industry definition that extends Abell's (1980) three dimensions to seven. He suggests that an integrated approach to market segmentation provides the foundation for conducting strategic group analysis in consumer markets. So, in strategic group research, we need a bottom-up approach that begins with a product-market segment. In each product market, real competition occurs at the brand level. This is the ground where actual competitive wars are fought, and this is where the rich dynamics of competition often come to light.
\end{abstract}

Key words: strategic group theory; resource-based theory; customer-based theory of management; market segmentation; price-quality segmentation; defining a business or industry

\section{Introduction}

Few ideas have caught the imagination of strategic management (SM) theorists more than the concept of strategic groups about which numerous empirical studies have been conducted. The two pillars of this theory are that: (1) intra-industry strategic groups actually do exist, and (2) performance of the firms depends generally on which group a firm belongs to (Barney \& Hoskisson, 1990).

The impetus for this activity was provided by the emphasis on research that explored how strategy is linked to performance (Ketchen \& Shook, 1996). This development occurred in the early seventies when SM research emerged from "essentially a descriptive, clinical orientation to one more concerned with the objectivity and methods of science” (Cool \& Schendel, 1987, italics added).

Y. Datta, Ph.D., professor emeritus, College of Business, Northern Kentucky University; research field: strategic management. 
The basic premise of strategic group theory is that most industries are not homogeneous, but consist of different groups of firms - each group with different resources - that follow similar strategies. The purpose of this stream of research is to examine the validity of their existence by testing whether there are significant performance differences among the groups (Barney \& Hoskisson, 1990).

Barney and Hoskisson (1990) take the position that strategic group research has not demonstrated the existence of strategic groups, or their relationship to firm performance. Leask (2007) also suggests that the link between performance and strategic group membership has yet to be established.

There are several reasons behind the generally disappointing results of strategic-group research (Thomas \& Venkatraman, 1988; Barney \& Hoskisson, 1990; Leask, 2007). First is the absence of a theoretical framework to determine what strategic variables to include in the analysis. Second, there has generally been little effort to determine the relative importance of different variables. Third, there is a lack of an effort toward making competitive strategy operational by building on a theoretical work, such as, Porter's (1980) generic strategies, or Miles and Snow's (1978) typology. Fourth, the question of defining what an industry is has not received much attention. Fifth, there is the use of cluster analysis techniques in a manner that leaves a lot to be desired.

The problems surrounding the use of cluster analysis in SM have already been discussed in considerable depth (Barney \& Hoskisson, 1990; Ketchen \& Shook, 1996; Leask, 2007). Thus, the author believes it is not necessary to explore this matter any further.

So, the author will devote his attention to the remaining issues listed above.

\section{Corporate, business, and functional strategies}

To address this question, we need to understand the relationship between corporate, business and functional strategies. While corporate strategy defines the businesses in which the firm will compete, business strategy determines how the company will compete in a given business. Thus, business strategy is concerned with identifying key resources and activities and the manner in which they will be deployed (Andrews, 1987, pp. 13-14).

In strategic group research, the general approach has been to include variables from different functional areas-e.g., manufacturing, finance, and marketing - rolled into a single package (Hatten, Schendel \& Cooper, $1978^{1}$; Datta, 1980). However, not much has been done to address the question of how these functional variables are interrelated, and how they dovetail into strategy as a whole (Thomas \& Venkatraman, 1988). Nor has much effort been made to examine whether some variables are more important than others (Datta, 1980; Barney \& Hoskisson, 1990).

\subsection{Hierarchical approach downgrades functional strategies and operations}

One notion that has been popular in some circles in SM is a hierarchical approach to strategy that assigns an inferior status to functional strategies (Bower, 1982; Datta, 1998). However, the way a function is performed may be central to the concept of an enterprise. Wal-Mart offers a dramatic example in support of Bower's view. With a relentless focus on customer satisfaction, Wal-Mart owes its amazing success to the company's inventory management system (Stalk, Evans \& Shulman, 1992; Datta, 1998).

Advocates of the hierarchical approach to strategy have also suggested that functional strategy is primarily concerned with efficiency rather than effectiveness. However, like goals and strategy, effectiveness and efficiency

\footnotetext{
${ }^{1}$ The authors have also included environmental variables in their analysis.
} 
cannot easily be separated from each other (Datta, 1998).

One of the most dramatic examples of how efficiency and effectiveness are closely intertwined is Toyota's revolutionary lean production system. This system shattered the long-standing myth in the U.S. auto industry that setup time is a long, time-absorbing process. This system not only reached higher levels of efficiency —and lower costs - but also a significant increase in effectiveness by raising the level of quality. In addition, it enhanced plant flexibility which allowed greater variety for customers - all at the same time (Datta, 1998). As Hamel and Prahalad (1994, p.12) remind us, it took U.S. automakers 40 years to decipher what this revolution was all about.

Another implication of placing functional strategies at the bottom of the ladder is separating operations from strategy (Datta, 1998). There are two major implications of this approach. One is that only top management can formulate strategy. However strategy formulation requires a contribution from everybody in the firm: from top to bottom (ibid). Second, such a view could have a negative effect on strategy implementation. For example, Wheelwright (1981) recognizes eight types of decisions in a manufacturing organization ${ }^{2}$. He points out that the top American managers considered the first four ${ }^{3}$ decisions that involve capital investment as strategic and therefore requiring top-management approval. However, they regarded the second four ${ }^{4}$ decisions as secondary in nature, and consequently delegated the responsibility for them to middle management. One unfortunate result of this policy was to send the wrong signal to middle managers: to regard decisions about quality and production planning as "swing" factors. That meant getting the production out the door to meet schedule deadlines even if the product didn’t meet the firm's own quality standards (Juran, 1978).

Wheelwright (1981) suggests that the stunning success of the Japanese in manufacturing is very largely due to a vital Japanese practice: treating operations as strategic (Datta, 1998).

\section{A customer-oriented theory of management}

In his classic book, The Practice of Management, first published in 1954, Drucker made a statement that was astounding at that time. He said the purpose of a business is to create a customer (Drucker, 1974, p.61; Datta, 1997):

"To know what a business is, we have to start with its purpose. Its purpose must lie outside of the business itself. In fact, it must lie in society since business enterprise is an organ of society. There is only one valid definition of business purpose: to create a customer" (italics in the original).

Levitt (1986, p. 137) also suggests that the purpose of a business is "getting and keeping customers" (italics added). In a similar vein, Biggadike (1981) believes that the concept of a customer can be both a philosophy and a practical guide (Datta, 1997).

Procter \& Gamble (P\&G), the leading consumer products company in the world, has listed five core strengths. The first in that list is a "deep understanding of consumers and placing them at the center of all decision making” (Lafley \& Charan, 2008, p.13; italics added).

\subsection{A modified stakeholder theory of the corporation}

Datta (1997) has extended Drucker's idea mentioned above by proposing a modified stakeholder theory of the corporation that is grounded in the notion of "customers-first, employees-second”. By placing shareholders

\footnotetext{
2 To that, we should add the plant location decision.

3 Capacity, facilities, vertical integration, and production technology and processes.

${ }^{4}$ Workforce, quality control, production planning and material control, and organization.
} 
behind customers and employees, D'Aveni and Gunther (1994, p.264), too, support this position. While an objective like enhancing shareholder value may capture the fancy of the top brass, it is likely to exert very little “emotional pull” on ordinary employees (Hamel \& Prahalad, 1994, p.135). However, customer value can excite and motivate even the rank and file (Datta, 1997).

\subsection{From transaction or exchange orientation to relationship focus}

Womack and Jones (1994) suggest that the idea of a company based on legal boundaries has become obsolete in today's global economy. Today's global competition is increasingly being driven by the system of lean production invented by Toyota. So, they propose a shift from lean manufacturing to the lean enterprise: a network of producer, customers, and suppliers closely connected in a common bond as one economic whole. The group's mission is to do everything involved in providing a good or service in a manner that yields maximum value to the customer (ibid; Datta, 1997).

Based on the idea mentioned above, Womack and Jones (1994) have made an impressive case for a business to manage costs along the entire economic chain: a need that is critical for gaining competitive advantage in today's global markets (Drucker, 1995a; Datta, 1997).

Teamwork and trust are central to the field of total quality management (TQM). As firms move from lean manufacturing to lean enterprise, trust is going to become even more important. However, management theorists have not had a favorable view of trust-based cooperation. Instead, they tend to rely on the transaction cost theory which is grounded in the opportunistic behavior of partners (Dean \& Bowen, 1994; Datta, 1997).

While management theorists have not accepted the idea of trust, marketers are pointing to a paradigm shift in marketing that involves a move away from exchange or transaction to concentrating on "building value-laden relationships and marketing networks" (Kotler, 1991, p.1; italics in the original). The traditional transaction-based system has a short-term focus on sales: an approach that does not build customer loyalty, so price sensitivity is high. In contrast, relationship marketing has a long-term orientation to build customer loyalty. Consequently, price sensitivity is lower (ibid, Datta, 1997).

\subsection{From functions and tasks to processes: A resource-based theory perspective}

Porter's (1985, chap. 2) concept of value chain is an important contribution to SM theory. He says that one should examine the activities a firm performs to figure out the sources of its competitive advantage. He points out that the value chain activities are the building blocks upon which a business can gain competitive advantage by creating value for the customer (ibid, p.38). Porter's ideas are part of what is known as the resource-based theory in SM (Datta, 1996; Barney, Wright \& Ketchen, 2001).

In an article — that Drucker (1995b, p.132) has described as pathbreaking—Prahalad and Hamel (1990) have introduced the notion of core competence. Core competence is created when a business has developed the ability to blend different technologies and functional skills into a single bundle that enables it to provide a specific benefit to customers. One example is Sony's expertise in miniaturization which provides the benefit of “pocketability” (Hamel \& Prahalad, 1994, pp.168-169, 199; Datta, 1996).

Stalk, Evans and Shulman (1992, p.62) propose what they call a new concept of corporate strategy: "capabilities-based competition”. They suggest that: (1) The building blocks of corporate strategy are not products and markets but business processes; (2) The competitive success of a company depends upon transforming its key business processes into strategic capabilities that provide superior value to the customer; (3) These capabilities require investments in support infrastructure that ties together and transcends strategic business units (SBUs) and functions. 
Stalk, et al (1992, p.58) cite the spectacular success of Wal-Mart, as reported earlier, to underscore how a capabilities-based strategy can transform a business. The key to Wal-Mart's success was "to make the way the company replenished inventory the centerpiece of its competitive strategy" (italics added).

How does the idea of "capabilities" differ from the notion of core competencies? Stalk, et al (1992, p.66) indicate that the two concepts are complementary, but different in nature. They suggest that while "core competence emphasizes technological and production expertise at specific points along the value chain, capabilities are more broadly based, encompassing the entire value chain”.

Hammer and Champy (1993, p.78) argue that the basic unit of a conventional business organization is the functional department: a collection of workers performing similar tasks. They say that these enterprises are following an antiquated theory of work organization that is based on the notions of division of labor, reliance on elaborate controls and managerial hierarchy. They contend that these ideas do not work anymore in today's constantly-changing global economy. So, they recommend a cross-functional organization that is committed to a process orientation. This outlook requires "concentrating on and rethinking end-to-end activities that create value for customers" (ibid, inside jacket).

3.3.1 Capabilities or resources must meet the market test

Stalk, et al (1992, p.62) point out that a "capability is strategic only when it begins and ends with the customer" (italics added). Likewise, Hamel and Prahalad (1994, p.204) argue that a core competence must make a "disproportionate" contribution to customer-perceived value, and core competencies are the skills that make it possible for a company to deliver a "fundamental" customer benefit.

However, internal capabilities or resources cannot be evaluated in a vacuum; they can be judged only within the context of an external environment. A company may not be able to know its capabilities beforehand without testing them first in the market place. Moreover, competencies are also related to both time and situation. Thus, over time what was once a core competence may become a "base-line” capability (Datta, 1997).

\section{An integrated approach to competitive strategy}

In the previous section, the author has laid the philosophical foundation for a customer-based theory of management. Now, let us try to give it a more practical shape.

\subsection{Marketing as the first entrepreneurial function}

Drucker (1974, chap.6) says that because its purpose is to create a customer, a business has only two entrepreneurial functions: marketing and innovation. He considers marketing as the first entrepreneurial function. He says marketing is so basic that it cannot be regarded just another function, but a concern that must permeate all areas of an enterprise. According to him, it is the lens through which one can see the whole business from the customer's point of view.

It is essential to point out that Drucker is not using marketing in the traditional sense of a function or discipline, but rather as a philosophy grounded in the customer (Datta, 1997).

\subsection{Innovation as the second entrepreneurial function}

Drucker (1974, pp.65-66) points out that it is not enough for a business to sell just any goods and services; it must provide better and more economic goods. However, only the customer can judge the merit of an innovation. Like marketing, innovation, too, cuts across the entire business (Datta, 1997).

Supporting Drucker's view, Levitt (1969) observes that the pursuit of innovation is part and parcel of the 
marketing concept (Datta, 1997).

\subsection{Customer-perceived quality central to competitive success}

According to the research emanating from the PIMS database, customer-perceived quality is far more fundamental to competitive position and profitability than any other factor (Gale, 1992; Buzzell \& Gale, 1987, p.7). Several other studies using this database have also reported the importance of quality (Datta, 2010a). A review of the long history of PIMS-based research has "consistently shown a strong, positive association between quality and profitability” (Buzzell, 2004, p.480; Datta, 2010a).

However, the importance of quality has not been fully appreciated in the SM literature. Dean and Bowen (1994) point out that whereas total quality management (TQM) supporters regard customer-driven quality central to business strategy, the traditional view in SM regards quality as only one among several variables. They add that SM researchers view TQM's definition of quality - “meeting or exceeding customers' expectations"-as too broad. So, they have adopted a narrower definition of quality: a view that seems to center around product performance and features.

Under TQM, customer satisfaction is considered as the most vital determinant of long-term success. However, management theorists have not paid much attention to the customer (Dean \& Bowen, 1994; Datta, 1997). One explanation for this may be that the planning literature has given prominence to position over perspective (Mintzburg, 1994, p.28). Another reason for this omission is that management theorists look at an organization from the top down, or from the inside out, but hardly from the outside in (Dean \& Bowen, 1994; Datta, 1997).

Hamel and Prahalad (1991) suggest that in today’s environment of constantly-changing market boundaries, the critical task for management is not just to meet customer needs, but to anticipate them. Garvin (1991) and Ackoff (1994, p.94) say the winning companies aim at "customer delight" by trying not only to exceed customer expectations, but even anticipating unsatisfied needs the customers themselves may not have realized they had.

\subsection{A proposed theoretical framework of competitive strategy}

As Porter (Datta, 1997) has pointed out, it is the external environment that determines what a business should do and what its strategy should be. So, a good practical way to recognize the significance of this perspective is to visualize competitive strategy in two interdependent dimensions: external and internal (Datta, 1980; Datta, 1997). It is the external strategy that should be considered as the primary dimension, because it reflects the needs of the customers and the market.

The internal strategy, on the other hand, is concerned with a company's resources and capabilities. However, it does not imply that the internal strategy is unimportant; it simply means that it is the external strategy that provides a sense of direction regarding how those resources and capabilities should be deployed.

\subsubsection{External competitive strategy}

Based on the foregoing discussion, the author presents below a framework of competition for consumer markets that he has called external strategy. As mentioned above, it should be regarded as the primary dimension of competitive strategy. It has an outside focus, and it revolves around the customer (Datta, 1978 ${ }^{5}, 1980$ ):

(1) Brand equity

(2) Research and development (R\&D) strategy

(3) Marketing strategy:

- Quality

${ }^{5}$ Instead of brand equity, the author uses the term "image strategy". 
- Price

- Advertising and promotion

- Channels of retail distribution and service

Ansoff \& Stewart ${ }^{6}$ (1967) have proposed the following scheme of R\&D strategy for a technology-based business:

(1) "First to market"

(2) "Follow the leader"

(3) "Application engineering”

(4) "Me too"

A business seeking market share leadership has a choice of two R\&D strategies: either "first to market" or “follow the leader" (Ansoff \& Stewart, 1967).

Marketing variables are the conduits through which a business tries to serve its customers' needs—and to communicate to them; and they are the bases upon which a business differentiates itself from the competition. They are also the characteristics customers often use to perceive differences between competing brands (Datta, 1996).

It is important to observe that a variable included as part of the external strategy may also be an internal resource or capability. One example is channels of retail distribution and service. While one represents a demand-side or customers' view of how a service or benefit is perceived, the other offers a supply-side perspective of how such a benefit or service is delivered (Datta, 1996).

\subsubsection{Importance of brand equity}

Underscoring the importance of brand equity, Hamel and Prahalad (1994, p.237) suggest that in today's highly competitive markets it is very important for a business to create a "share of mind" among global customers. They say that what convinces a buyer to purchase a product from "Sony, Canon, or Toyota is less the length of the warranty period than the strength of the quality warrant implicit in the brand" (italics added).

Benefits that a brand can yield can be not only tangible but intangible as well. As mentioned above, the very name of a famous brand can be reassuring to a customer when buying a product, especially if the purchase price is substantial. Other important benefit of brand equity is brand loyalty (Aaker, 1991, pp.16-17). Testimonial from a reputable organization can also add considerably to the reputation of a brand. An example is P\&G's Crest toothpaste securing the first-ever endorsement from the American Dental Association (Datta, 1996).

Another benefit may be tied to a product's use or association (Aaker, 1991, pp.16-17; Datta, 1996). One example is the old reputation of Arm \& Hammer's baking soda as a deodorizer and freshener: a standing that enabled Church \& Dwight to successfully launch its Arm \& Hammer Dental Care toothpaste. While, the market-share leaders - P\&G and Colgate - were primarily focusing on therapeutic benefits, Arm \& Hammer positioned its toothpaste on a different dimension—aesthetics—by emphasizing the benefit of "clean and fresh" feeling (Datta, 1996).

\section{Making competitive strategy operational}

\footnotetext{
${ }^{6}$ The "First to market" strategy calls for strength in research and development. The "Follow the leader" strategy requires a focus on development and is suitable when the product enters the growth phase. The "Application engineering" strategy requires substantial design and engineering capability and is appropriate when a product reaches the maturity phase. For "Me too" a business needs superior manufacturing efficiency and cost control.
} 
As mentioned earlier, one of the problems in strategic group research has been that competitive strategy has not been made operational. This is what we intend to do here. However, before we can do that, we need to do two things: (1) have a brief discussion of Porter's cost leadership and differentiation strategies, and (2) examine the case for an integrated approach to market segmentation.

\subsection{Porter's cost leadership and differentiation strategies}

A major drawback of Porter's generic strategies is that they are too broad. He presents a narrow view of differentiation with a unique product—-sold at a premium price—on the one hand, and a "standard, or no-frills" product on the other (Datta, 2010a).

Contrary to Porter's views, a differentiation strategy based on superior quality compared to competition is more profitable than cost leadership strategy. It can lead a business to become a market share leader as a result of which it may even become a low-cost leader (Datta, 2010a).

Mintzburg (1988, p.16) says that Porter's cost leadership strategy should be called "price differentiation" strategy because it is based on a price that is lower than that of the competition. He suggests that business strategy has just two dimensions: differentiation and scope. Thus, setting scope aside competitive strategy has only one component: differentiation. So, the key question is "not whether to differentiate, but how" (Datta, 2010a; italics in the original).

The answer is that customer-perceived quality should be the cornerstone of competitive strategy because it is far more critical to long-term success than any other factor, as stated earlier. Second, a business should cater to the middle class by competing in the mid-price segment and offering quality that is better than that of the competition at a somewhat higher price (Datta, 2010a): an idea we will elaborate on a little later.

\subsection{An integrated approach to market segmentation}

Each market has two sides: demand and supply. However, marketers have traditionally adopted a rather limited view of market segmentation that is demand oriented. They define market segmentation in terms of "people" characteristics, e.g., demographics, social class, psychographics, etc. An opposite perspective, which may be called "product" segmentation, is a supply-oriented approach that begins with product characteristics, such as price-quality segmentation, product quality or benefits, physical product attributes, channels of distribution, technology and so on. This view is generally concerned with a company's resources and capabilities: a subject that is known as the resource-based theory in SM (Datta, 1996).

So, what we need is an integrated approach to market segmentation that includes both the demand and supply sides of the competitive equation, "where 'people' [customer] and 'product' characteristics are not mutually exclusive paths to market segmentation, but, rather, two sides of the same coin” (Datta, 1996, p.799).

The "product" characteristics approach is an easier and more actionable way of analyzing how a market is-or can be-segmented than the traditional marketing approach. Also, as we shall later see, an integrated approach to market segmentation provides the foundation upon which to perform strategic group analysis in consumer markets (ibid).

\subsection{An operational framework of competitive strategy}

As mentioned earlier, customer-perceived quality is the most important contributor to the long-term success of a business. Quality, however, cannot meaningfully be separated from price. Regardless of the level of quality, customers generally won't buy products they cannot afford, nor pay for quality they may not need. Also for many products, objective measures of quality are either not available, or are not easy to comprehend. So, customers often use price as a symbol of quality to perceive differences among competing brands, and businesses regularly 
use relative price to differentiate themselves from their competitors (Datta, 1978; Datta, 1996).

Most consumer markets can be partitioned in three basic price-quality segments: premium, mid-price and economy (Datta, 1996). So, a business with the aim of becoming a market share leader has to answer two crucial questions. First, which price-quality segment—premium, mid-price, economy—is the best vehicle for market share leadership for the product-market the business is competing in? Second, what is the price level compared with the competitors to position itself within that segment?

\subsubsection{The economy segment}

The economy segment implies competing on low price. It is quite possible to become a market share leader following this strategy. However, any strategy anchored in low price is unlikely to lend a quality-image to a brand. And because of the low price, it would be very difficult to maintain a level of quality that is better or even at par with that of the competition. Thus such a strategy may not be very profitable and hard to sustain in the long run.

\subsubsection{The premium segment}

The premium segment is generally not conducive to market share leadership (Porter, 1980, p.38; Datta, 2010a). However, there are some exceptions. For example, in spite of its premium price, Caterpillar is the leading producer of construction equipment (Porter, 1980, p.38). This is an industry where downtime is very costly. That is why customers are quite willing to pay a premium price for Caterpillar's machines because the company offers high-performance durable equipment backed by outstanding service (ibid).

Drucker (1987) suggests that high price itself is an important factor in the desirability of what he calls status goods (e.g., perfume, liquor, etc.). So, high market share and premium price may potentially be a viable combination for some status goods.

\subsubsection{The mid-price segment is the best choice for market share leadership}

Finally, we turn to the mid-price segment which caters to the middle class. This segment represents a price range most middle-class consumers would find affordable. This, too, is the socio-economic segment that represents about $40 \%$ of households in America (Datta, 2010b). It is also the same customer group that P\&G has successfully served in the past (Lafley \& Charan, 2008, p.12). Thus, this price-quality segment is generally the most appropriate vehicle for achieving market share leadership (Datta, 2010a).

\subsubsection{Superior quality at a somewhat higher price than the competition}

While offering superior quality than the competition is critical to business success, it should be offered at a price-level higher than the competition- "principal competitors"-a standard employed in the PIMS database (Buzzell, 2004, p.480). This is necessary for two reasons: (1) to maintain an image of quality, and (2) to ensure that the strategy is profitable and sustainable.

Although higher quality does deserve a "price premium", it should not be excessive. That is why P\&G follows a pricing policy that allows its superior-quality brands to command a "modest premium" from loyal customers (Lafley \& Charan, 2008, p.9).

So, how do we operationalize the above pricing guideline? We see three alternatives to address this problem. One is to position the brand at the top of the mid-price segment. However, depending upon the competition in the segment, a price level at the upper end of the segment could mean a "price premium" that may be too much, and may not therefore lead to market share leadership because such a price may be economically out of reach for many middle-class consumers.

The second alternative is to set the price level that is above industry average. Although it is an elegant solution, the industry average is, nevertheless, a statistical abstraction over which management has little control. 
When a business tries to position a brand in terms of relative price within a price-quality segment, it is very likely to do so keeping in mind real competitors rather than a statistical average.

So, the best choice is the third alternative which calls for a relative price that is somewhat higher than that of the nearest competition. It is both practical and easy to apply. Instead of an abstraction, it represents the concrete reality of individual competitors.

\section{Defining what is an industry or business}

The early $\mathrm{IO}^{7}$ strategic-group research involved multi-industry studies. However, majority of this research in SM has focused on a single industry (Leask, 2007).

Leask (2007) points out that comparing strategy of firms across multiple industries is likely to capture only broad differences in firm performance. Such an approach is likely to miss the nuances of strategy that lead to differences in performance among firms. So, he argues that because strategic choice is context specific, the most suitable level for strategic group research is the industry.

But the key question is what do we mean by an industry? For example, Barney \& Hoskisson (1990) conducted a study of the food-processing industry involving 27 firms to explore the existence of strategic groups. This study includes firms in such diverse businesses as makers or processors of chocolate, beer, soup, cheese, cereals, flour, chicken and so on. Yet, most of these firms do not directly compete with each other. They really belong to different "industries": each with a different technology, and each serving a different customer need.

A successful business strategy has to be "specific, precise and far-ranging” (Hamermesh, Anderson \& Harris, 1978; Datta, 1980). Thus, a study where an industry is defined very broadly is likely to overlook the subtleties of competition (Leask, 2007).

\subsection{Strategic groups and mobility barriers}

As mentioned earlier, the strategic group theory suggests that most industries consist of different groups of firms — each group with different resources — that follow similar strategies.

A central theme of this theory is the notion of mobility barriers that involves a hierarchy of strategic groups where the more profitable ones are protected by a higher level of mobility barriers. Thus, strategic groups may be described as "stable intra-industry structures" separated by mobility barriers that are expected to produce significant performance differences between them (Leask, 2007, p.192; italics added).

Contrary to the general assumption in the field, Hatten and Hatten (1987) argue that mobility barriers are asymmetric - at-least in consolidating industries. First, they say that large or efficient firms may be able to copy or overpower smaller firms within the latter's niches at low cost, while it may be much more difficult for smaller firms to strike back. Second, they have questioned the assumption that all firms within a strategic group pursue similar strategies. They suggest that these firms do not necessarily have to compete against each other, and that some may successfully compete against a common, perhaps a larger rival, in another strategic group. Third, they propose the idea that an industry is not a group of firms, but a set of populated and unpopulated niches, and the notion of contestability that can help explain the evolution of industry structure.

Another important point is that barriers for entry and exit may be quite different. It may be far easier to get into rather than out of a group (Hatten \& Hatten, 1987).

Porter (1980, p.129) makes an observation that is worth noting. He says that an industry could have only one

\footnotetext{
${ }^{7}$ Industrial Organization.
} 
strategic group if every firm in the industry follows same or similar strategy. On the other hand, each individual firm could be a separate strategic group by itself.

\subsection{Trend toward competing in multiple price-quality segments}

As the author has said earlier, an integrated approach to market segmentation offers the foundation for conducting strategic group analysis in consumer markets. Let us assume that we have an industry with a single product-market which could be partitioned into three basic price-quality segments: premium, mid-price and economy. Then we could potentially have three strategic groups in the industry corresponding to each price-quality segment.

However, in many product markets it is not uncommon for firms to compete in multiple price-quality segments. Perhaps the most notable example is the U.S. lodging industry. For example, Marriott, long a major player in the premium segment, decided to expand its presence in the U.S. through the mid-price Courtyard chain and the economy Fairfield ${ }^{8}$ chain (Datta, 1996). Another example is Whirlpool Corp. in the major appliance industry. During the eighties, the company acquired the economy Roper line and the premium KitchenAid line to complement its mid-price Whirlpool brand (Datta, 1996). Still another example is Anheuser Busch Co. which has long had three beer brands in its arsenal: Michelob (premium), Budweiser (mid-price) and Busch (economy).

A study of the U.S. toothpaste market in 1996 provides other examples. Colgate Palmolive had three brands: the upper-mid price Viadent, the mid-price Colgate and the economy Ultra-brite. Similarly, Unilever had four brands that included the upper-mid price Mentadent, the mid-price Close-up, and the economy Aim and Pepsodent: all of which were sold to Church \& Dwight in 2003. P\&G had two mid-price brands: Crest and Gleem (Datta, 1996).

In the company's 2009 annual shareholder report ${ }^{9}$, P\&G's president and CEO, McDonald, has made a notable observation. He says that the company will expand its categories vertically to serve more consumers at more price points-into the premium end of our markets and into the "value-priced" segment.

P\&G’s 2009 annual report points out that many of the product segments in which the company takes part are differentiated by price (referred to as "super-premium, premium, mid-tier value and low-tier economy" products). In other words, what the report seems to suggest is that many markets in which P\&G operates consist of four price-quality segments: super-premium, premium, mid-price and economy. However, the report also says that P\&G usually competes in all but the economy segment.

\subsection{Abell's framework: Defining a business or industry}

In today's fast-moving global economy market boundaries are changing constantly. So, defining a business in terms of the current product, e.g., a railroad business or a copier business is too narrow. While such a view may be adequate today, it is unlikely to be so tomorrow. On the other hand, defining a business such as a transportation business is too broad because it does not provide a common thread between the current and future markets (Ansoff , 1965, chap. 6).

Abell (1980, chap.2) says that a business can be defined along three dimensions: (1) customer groups served, (2) customer functions served, and (3) technologies utilized. He points out that Ansoff (1965, pp.105-106) also implies the same three dimensions. Datta (1996), too, supports the ideas of Abell and Ansoff.

To understand how Abell's view of defining a business can be applied in practice, we decided to look at the

\footnotetext{
${ }^{8}$ Marriott positioned the Fairfield chain at the upper end of the economy segment.

${ }^{9}$ http://annualreport.pg.com/annualreport2009/_downloads/PG_2009_AnnualReport.pdf.
} 
product-market portfolio of a large diversified consumer products company. We could not have chosen a better source than $P \& G$ whose product-market structure can be found in its 2009 annual report.

P\&G has three global business units (GBUs): Beauty \& Grooming, Health \& Well-being, and Household Care.

\section{Personal Care}

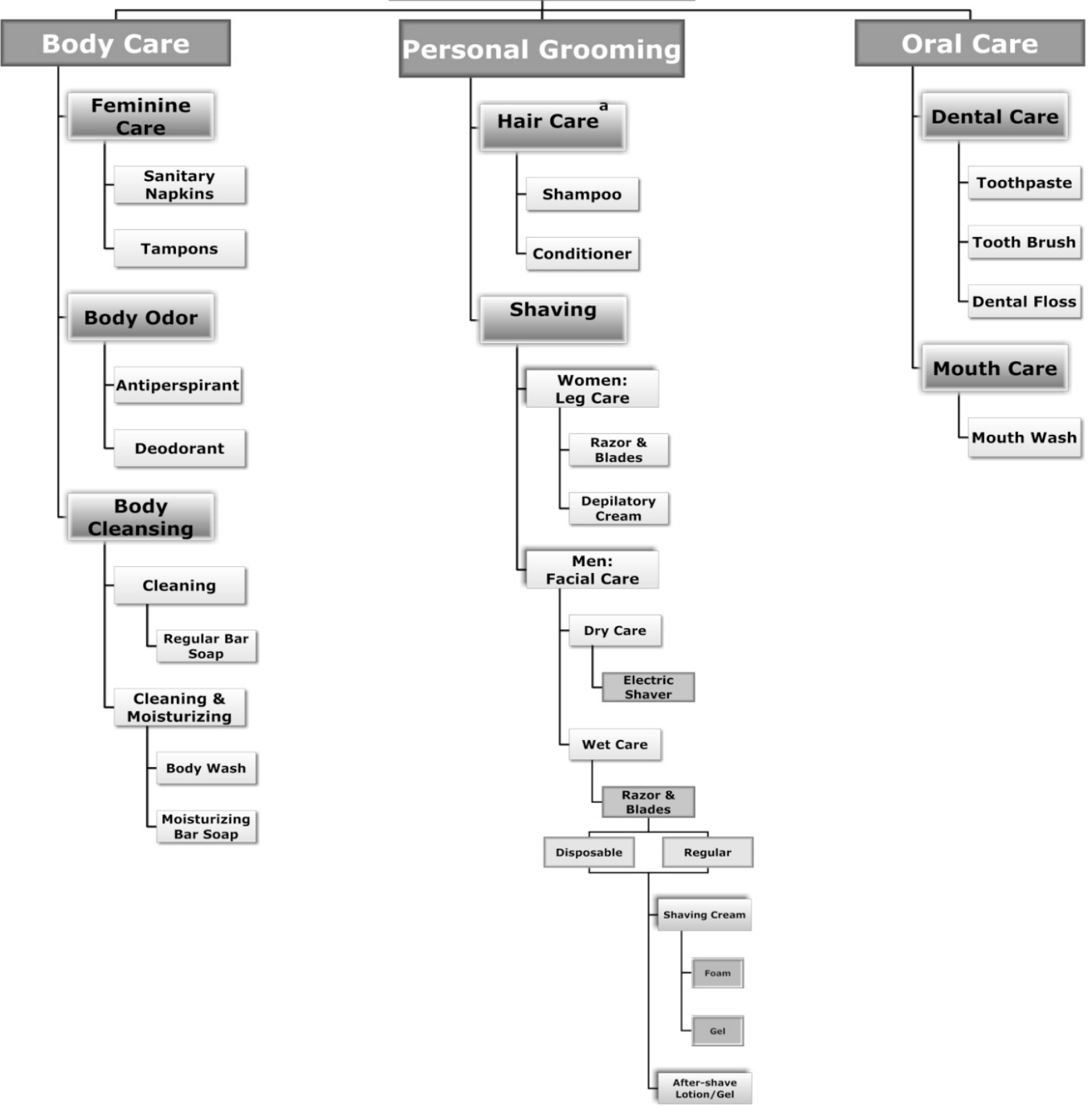

Fig. 1 XYZ Corp. : Personal Care Strategic Business Group

Note a: We have not included Hair Color as part of personal grooming because we feel it belongs to the Beauty GBU.

Fig. 1 contains our representation of "Personal Care": a strategic business group (SBG) of a hypothetical company. This fictional SBG has three sub-groups: Personal Grooming, Body Care and Oral Care. 
Grooming is described in the dictionary as meaning "to care for the appearance of; to make neat and trim". ${ }^{10}$ Since Personal Grooming is related to external appearance we have recognized two major needs: Hair Care and Shaving.

While Personal Grooming is all about outer appearance, Body Care is about what is under the clothes, i.e., personal hygiene. It involves three specific needs: Body Odor, Personal Cleansing, and Feminine Care. Oral Care has two functions: Dental Care and Mouth Care.

So, now if we take an overview of Fig. 1, we can see seven distinct businesses that may be described as SBUs: Hair Care, Shaving, Feminine Care, Body Odor, Body Cleansing, Dental Care and Mouth Care, each serving a different customer need.

There are some differences between how we have grouped businesses in Figure 1, and how they are portrayed in P\&G's annual report. While P\&G has included Feminine Care and Oral Care under the Health \& Well-being GBU, we have shown them as part of the Personal Care group which comes under P\&G's Beauty \& Grooming GBU. Also, we have recognized depilatory cream as one of two options for leg care for women, even though P\&G does not compete in this product-market segment. Finally, while Hair Care-along with Hair Color-is part of the Beauty sub-group under P\&G, we have included Hair Care as part of Personal Care under the Personal Grooming sub-group.

\subsection{Extending Abell's framework}

We have extended Abell's framework from three to seven dimensions (see Fig. 2). Instead of treating "customer function" as a single dimension, we have split it into four parts: customer need, customer benefit, customer function and customer mission. Another factor that we have added is "channels retail distribution and service”: an important part of external strategy, as indicated earlier.

We explain below the rationale for adding four more dimensions to Abell's framework. To make it easier for us to present our case we provide below a practical application of this new framework (see Fig. 2) around the Shaving SBU (see Fig. 1).

First is the customer need: the starting point for market segmentation (Datta, 1996). As Fig. 2 shows, this is personal grooming.

Next is the customer benefit. Product benefits-together with customer and situation-provide the most useful and practical underpinning for segmenting a market (Datta, 1996). As stated above, the benefit of personal grooming is "to look neat and trim".

After that is the customer group. The two major groups served by this SBU are men and women.

The customer function represents the next level. According to American Heritage dictionary, a function ${ }^{9}$ means a "specific occupation or role", e.g., "the function of a teacher" or "the role of a parent". The two functions that satisfy this definition are: facial care for men and leg care for women (Fig. 2).

The next level is the customer mission. We have used the word mission in a manner that is employed by the military. It implies performing a very specific and narrowly-defined task: for example, a "combat mission," or a "search mission." Following the customer function for men-defined as facial care-the customer mission to accomplish that objective is "shave hair" (see Fig. 2).

The next stage is that of technology or technologies. For example, there are two technologies available for shaving men's hair: a dry shave with an electric shaver, or a wet shave with a razor and blades. For wet shave, you

\footnotetext{
${ }^{10}$ The American Heritage dictionary of the English language (3rd ed.). (1992). Boston: Houghton Mifflin Co.
} 
need shaving cream ${ }^{11}$ which comes as foam or gel. In addition, you may also require after-shave lotion/gel (see Fig. 1).

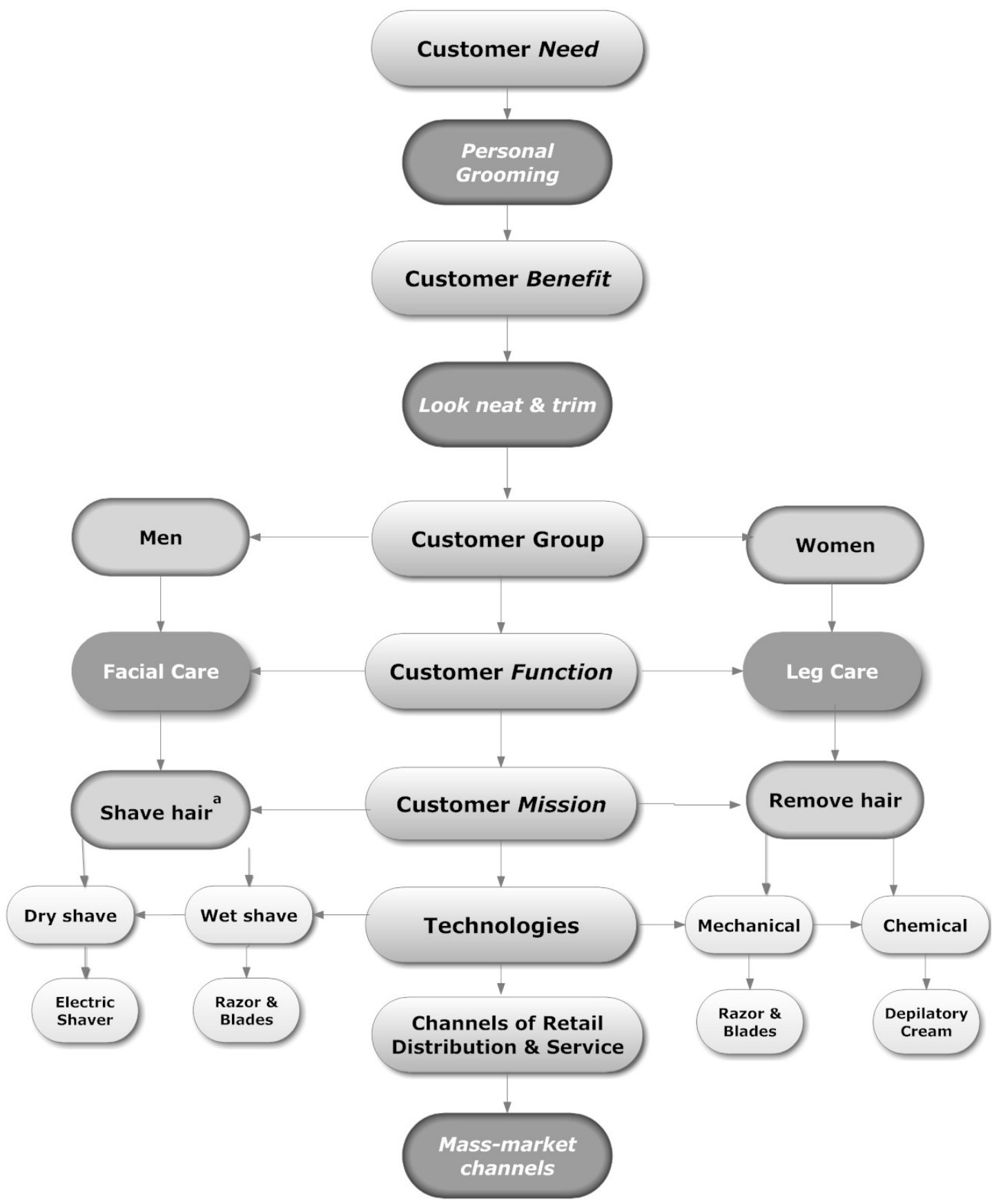

Fig. 2 Defining a business or industry: Extending Abell's framework

Note a: Shave hair comfortably, without irritation, cuts or nicks.

Finally, we have the channels of retail distribution and service. As Fig. 2 shows, the products that constitute the Shaving business are distributed through mass-market channels, e.g., super-markets, discount stores,

${ }^{11}$ P\&G (Gillette) has just introduced a pre-shave thermal face scrub for men. 
warehouse clubs, drug stores, etc.

To sum up, it is clear from the above discussion that Shaving is a multi-technology multi-product industry or business that serves two major customer groups—-men and women — each with its own distinct needs. While the primary driver of this industry is safety razor and blade technology, it includes substitutes as well that are based on different technologies. In addition, it also involves other products that support the broader mission of shaving.

\section{Conclusion}

Barney and Hoskisson (1990) have been very critical of the strategic group research. They suggest that it has neither demonstrated the existence of strategic groups, nor their relationship to firm performance. The main reason behind the disappointing results is the lack of a theoretical framework: what strategic variables to incorporate in the analysis, their relative significance, the definition of an industry, and how to make competitive strategy operational.

In response to this criticism, the author first presents a customer-oriented theory of management, and submits that, like P\&G, understanding customers should be the principal focus of a business.

Second, the author proposes an integrated approach to competitive strategy. Because customer-perceived quality is far more crucial to long-term success than any other factor, it ought to be the foundation of competitive strategy. The author suggests that competitive strategy be visualized in two interdependent dimensions: external and internal. It is the external strategy that should be considered as the primary dimension because it reflects the customers' view, and provides guidance regarding how the internal resources should be used.

Next, the author presents an operational framework of competitive strategy. He suggests that the best route to market share leadership is to compete in the mid-price segment, offering better quality than the competition —at a somewhat higher price: (1) to maintain an image of quality, and (2) to ensure that the strategy is profitable and sustainable.

Finally, the author proposes a framework of business or industry definition that extends Abell's (1980) three dimensions to seven.

Based on this broader framework, the author found that Shaving is a multi-technology multi-product industry or business. While the principal driver of this industry is safety razor and blade technology, yet it also relies on: (1) other technologies that provide substitutes for razor and blades, and (2) other products, such as shaving cream, that support the primary mission of shaving.

An integrated approach to market segmentation provides the building blocks for strategic group analysis in consumer markets. So, in strategic group research, we need a bottom-up approach that begins with a product-market segment: a venue where real-life competition occurs at the brand level. This is the arena where actual competitive wars are fought, and this is where the rich dynamics of competition often reveal themselves.

\section{References:}

Aaker, D. A.. (1991). Managing brand equity: Capitalizing on the value of a brand name. New York: Free Press.

Abell, D. F.. (1980). Defining the business: The starting point of strategic planning. Englewood Cliffs, N.J. : Prentice Hall.

Ackoff, R. L.. (1994). The democratic corporation. New York: Oxford University Press.

Andrews, K. R.. (1987). The concept of corporate strategy (3rd ed.). Homewood, IL: Irwin.

Ansoff, H. I.. (1965). Corporate strategy: An analytic approach to business policy for growth and expansion. New York: McGraw Hill. 
Ansoff, H. I. \& Stewart, J. M.. (1967). Strategies for a technology-based business. Harvard Business Review, 45(6), 71-83.

Barney, J. B. \& Hoskisson, R. E.. (1990). Strategic groups: Untested assertions and research proposals. Managerial and Decision Economics, 11, 187-98.

Barney, J., Wright, M. \& Ketchen, D. J, Jr... (2001). The resource-based view of the firm: Ten years after 1991. Journal of Management, 27, 625-41.

Biggadike, E. R.. (1981). The contributions of marketing to strategic management. Academy of Management Review, 6(4), 621-632.

Bower, J. L.. (1982). Business policy in the 1980's. Academy of Management Review, 7(4), 630-638.

Buzzell, R. D.. (2004). The PIMS program of strategy research: A retrospective appraisal. Journal of Business Research, 57(5), 478-483.

Buzzell, R. D. \& Gale, B. T.. (1987). The PIMS principles. New York: Free Press.

Cool, K. O. \& Schendel, D.. (1987). Strategic group formation and performance: The case of the U.S. pharmaceutical industry, 1963-1982. Management Science, 33(9), 1102-1124.

Datta, Y.. (1978). A model of competitive strategy in the TV Set industry. Academy of Management Best Papers Proceedings.

Datta, Y.. (1980). New directions for research in business strategy. Journal of General Management, 6(1), 48-60.

Datta, Y.. (1996). Market segmentation: An integrated framework. Long Range Planning, 29 (6), 797-811.

Datta, Y.. (1997). Customer: Big gap in management theory. In: Rahim, M. A., Golembiewski, R. T. \& Pate, L. E. (Eds.), Current topics in management, 2. Greenwich, CT: JAI Press, 189-220.

Datta, Y.. (1998). The mechanistic foundations of strategic management: Time for a radical change. In: Rahim, R. A., Golembiewski, R. T. \& Lundberg, C. C. (Eds.), Current topics in management, 3. Stamford, CT: JAI Press, 125-150.

Datta, Y.. (2010a). A critique of Porter's cost leadership and differentiation strategies. Chinese Business Review, 9(4), 37-51.

Datta, Y.. (2010b). Rising economic inequality and class divisions in America: A socio-economic class lifestyle profile. Oxford Journal, Fall (forthcoming).

D’Aveni, R. A. \& Gunther, R.. (1994). Hypercompetition: Managing the dynamics of strategic maneuvering. New York: Free Press.

Dean, J. W., Jr. \& Bowen, D. E.. (1994). Management theory and total quality: Improving research and practice through theory development. Academy of Management Review, 19, 392-418.

Drucker, P. F.. (1974). Management: Tasks, responsibilities, practices. New York: Harper \& Row.

Drucker, P. F.. (1987). Drucker on management. Management Today, September, 58-59, 110.

Drucker, P. F.. (1995a). The information executives truly need. Harvard Business Review, 73(1), 54-62.

Drucker, P. F.. (1995b). Managing in a time of great change. New York: Truman Talley Books/Dutton.

Gale, B. T.. (1992). Quality comes first when hatching power brands. Planning Review, 20(4), 4-9.

Garvin, D. A.. (1991). How the Baldridge award really works. Harvard Business Review, 69(6), 80-93.

Hamel, G. \& Prahalad, C. K.. (1991). Corporate imagination and expeditionary marketing. Harvard Business Review, 69(4), 81-92.

Hamel, G. \& Prahalad, C. K.. (1994). Competing for the future: Breakthrough strategies for seizing control of your industry and creating the markets of tomorrow. Boston: Harvard Business School Press.

Hamermesh, R. G., Anderson, M. J., Jr. \& Harris, J. E.. (1978). Strategies for low market share businesses. Harvard Business Review, 56(3), 95-102.

Hammer, M. \& Champy, J.. (1993). Reengineering the corporation: A manifesto for business revolution. New York: HarperBusiness.

Hatten, K. J., Schendel, D. E. \& Cooper, A. C.. (1978). A strategic model of the U.S. brewing industry: 1952-1971. Academy of Management Journal, 21(4), 592-610.

Hatten, K. J. \& Hatten, M. L.. (1987). Strategic groups, asymmetrical mobility barriers and contestability. Strategic Management Journal, 8, 329-342.

Juran, J. M.. (1978). Japanese and Western quality: A contrast in methods and results. Management Review, 67(11), 25-28, 39-45.

Ketchen, D. J., Jr. \& Shook, C. L.. (1996). The application of cluster analysis in strategic management research: An analysis and critique. Strategic Management Journal, 17, 441-458.

(to be continued on Page 36) 